\title{
Relationship Between Career Planning and Major Identity of Preschool Education Major Undergraduates --Based on Investigation in H University
}

\author{
Wanyan Sun
}

School of Education, East China Normal University, Shanghai 200062, China 2940079073@qq.com

\section{ABSTRACT}

Career planning and major identity of preschool education major undergraduates play an indispensable role in the development of national preschool education system. This study explores the relationship between career planning and major identity. A sample of 105 preschool education major undergraduates was used and typical students were interviewed as well. The main results are shown as following: Firstly, career planning of preschool education major undergraduates is higher than average level, including career cognition with the highest score and career planning knowledge mastery with the lowest score. Secondly, major identity is ordinarily active. The score of major cognition is the highest and the score of major environment cognition is the lowest. Thirdly, the positive correlation between career planning and major identity is significant. However, there is no significant difference in grades. On the basis of results, this study proposes specific recommendations from three aspects which is strengthening self-cognition and surrounding environment understanding, enhancing career planning knowledge and skills, and improving students' preschool education identity.

Keywords: preschool education, career planning, major identity

most suitable career goals, and make plans for this.

\section{LITERATURE REVIEW}

\subsection{Concept}

\subsubsection{Career Planning}

Career planning was first introduced by Rothwell. He defines it as drawing up a plan to achieve career goals which is subject to individual and objective conditions. ${ }^{[1]}$ It was then defined by Shuangping Luo as the combination between individual and social organization development. Based on the comprehensive analysis of subjective and objective factors, individual plans appropriate and reasonable steps of occupation, education and training for the realization of one's career goal. ${ }^{[2]}$ Major divided career planning into nine steps: 1 . set up career goals 2 . assess requirements of goals 3. refine the goals 4 . propose plans 5. predict results 6 . select the best scheme 7.carry out the scheme 8 . assess effects 9 . feedback predetermined goals and adjustment. ${ }^{[3]}$ As can be concluded from the definition of domestic and foreign scholars, the purpose of career planning is to achieve one's own career goals. In order to do this, individual needs to set goals, refine goals, implement actions and adjust goals. On the basis of that, one also needs to consider personal factors and environmental factors. In this study, career planning is defined as: preschool education graduates consider individual factors (values, interests, personality, etc.) and career environment (development prospect, salary and social status, etc.) with comprehensive measure, determine the

\subsubsection{Major Identity}

Tickle proposes that major identity is learner's acceptance and recognition about his/her own major, which can be demonstrated as the learners' love towards major combined with their own interests, hobbies and specialties. Learner is willing to explore the major with an active attitude. ${ }^{[4]}$ Chinese scholar Jing Yang related major identity and career together on the basis of the theory of Tickle. She defined students' major identity as that they genuinely love their major, have positive comments on their major, and are willing to take their major as their future career development. ${ }^{[5]}$ Through sorting out the existing concepts, major identity is mainly manifested in learners' positive attitude and behaviors towards major, and is related to career development. The major identity of this study is defined as: preschool education undergraduates accept and recognize the major, conduct relevant learning and social practice with a positive attitude, and are willing to take preschool education as the direction of future career development.

\subsection{Previous Study about Career Planning and Major Identity}

This study mainly discusses the correlation between career planning and major identity, so this section is divided into three parts: study of career planning, study of major identity, and the correlation between career planning and major identity. 


\subsubsection{Career Planning}

Wanying Dong[6], Yan Wang[7], Hui Zhan ${ }^{[8]}$ analyzed problems occurring in the career planning of Chinese undergraduates. From individual's perspective, the problems include the lack of self-cognition, the absence of planning awareness, blurred goals and dearth of executive competence. From university's perspective, the problems include the ineffectiveness of curriculum construction system and uneven of teachers' quality. Hui Zhan ${ }^{[8]}$ and Huiyu Zhang ${ }^{[9]}$ studied the influencing factors of career planning, and pointed out that career planning of normal university students and preschool education undergraduates is significantly affected by personal factors (self-recognition, career recognition and environmental recognition, etc.) and environmental factors (university support, social evaluation, etc.). There are also scholars analyzed and studied strategies of career planning for university students. From the personal level, Xiaoyu Zhang ${ }^{[9]}$ and Dan $\mathrm{Wu}^{[10]}$ advised the undergraduates to strengthen career planning awareness, improve major qualities and participate in social practice actively. From the perspective of universities and colleges, Wanying Dong ${ }^{[6]}$ and Xiange $\mathrm{Shi}^{[11]}$ proposed that the university should strengthen the training of college students 'practical ability, develop useful curriculum system, and improve the construction of teachers' related competence. From the social level, Dan $\mathrm{Wu}^{[10]}$ put forward the importance of family career planning education. She advised to reposition the role of teachers and optimize management systems.

\subsubsection{Major Identity}

In terms of the major identity of preschool education students, the results of our research are not optimistic. Ruihong Zuo's research on undergraduates in preschool education found that the level of major recognition is not high. The main negative factors are the narrow career development space, the inability to realize the value of life and the low salary. The reports of preschool education undergraduates and college students written by Li Zhang ${ }^{[12]}$ and Yan $\mathrm{Chen}^{[13]}$ demonstrate that even though most of students are willing to choose an occupation relating to their major after graduation, few want to work as a kindergarten teacher. There are also some studies about the influencing factors of preschool education undergraduates. It is found by Xiaoli Liu ${ }^{[14]}$, Yu Long ${ }^{[15]}$ and Yuanzhen $\mathrm{Mu}^{[16]}$ that grades, major application, hometown, diploma level, learning conditions and school level all have an impact on major identity of students.

\subsubsection{The relationship between career planning and major identity}

Through sorting previous study, it can be found that the study exploring relationship between career planning and major identity is relatively few. Yi Wang discovered that the positive relation between career planning and major identity is significant. ${ }^{[17]}$ Rong An put forward that higher vocational colleges should strengthen career planning based on major identity nurturing. ${ }^{[18]}$

To conclude, in terms of research subject, most of studies focus on the university and college students, and there are few related studies conducted on normal students or students of preschool education majors. Although preschool education undergraduates belong to university students group, most scholars only focus on the common parts between university students and preschool education undergraduates, ignoring the particularity of normal students. In term of research theme, most studies only concentrate on major identity or career planning, and neglect the correlation between these two variables. However, this study notices the correlation between major identity and career planning and explores it.

\section{METHODS}

\subsection{Issues}

This study concentrates on the relationship between career planning and major identity. To be specific, this research includes the current status of career planning and major identity of sophomore, junior, and senior students in preschool education, and the relationship between career planning and major identity.

\subsection{Participants}

The undergraduate students of the preschool education department of $\mathrm{H}$ University were selected. The sampling process completely considered the distribution of demographic characteristics of the sampled population, such as the grade and hometown. A total of 106 questionnaires were distributed and 105 of them were effectively recovered, with an effective recovery rate of $99 \%$. Among them, there are 6 males $(5.66 \%)$ and 100 females $(94.34 \%)$, which is in line with the overall distribution of preschool education major girls more than boys. Also, from the grade level, 34 sophomores $(32.08 \%), 40$ juniors $(37.74 \%), 32$ seniors $(30.19 \%)$ are included. In addition, several extreme cases in the questionnaire were selected to have an interview. Two students with lower major recognition and career planning level each from three grades were interviewed.

\subsection{Research Methods}

\subsubsection{Questionnaires}

By distributing questionnaires sophomore, junior, and senior students of preschool education majors in H University, this study recognizes the major identity and career planning of 
preschool education students in general. The questionnaire of this study is composed of three parts: the first part is basic information; the second part is the career planning questionnaire for preschool education students; the third part is the major identity of preschool education students Questionnaire.

\subsubsection{Career planning questionnaire for preschool education students}

Referring to Dan Wu's Questionnaire for Current Situation of Career Planning of Preschool Education Majors ${ }^{[10]}$ and Kaibing Wu's Questionnaire for Current Situation of College Students Career Planning[ 19], this study compiles a questionnaire about preschool education career planning. It consists of a total of 21 projects, which divides career planning into four dimensions: self-cognition, environmental awareness, career planning knowledge mastery and career cognition. Applying Likert's five-point scale scoring method, all items are averaged. The higher the score is, the better the career planning is to have. In this questionnaire, the internal consistency coefficient $\alpha$ of this scale is 0.61 .

\subsubsection{Major identity questionnaire for preschool education students}

Referring to Yu Long's major Identity Questionnaire for Preschool Education Students in Normal Universities ${ }^{[15]}$, this study complies with a particular questionnaire. A total of 22 items consist it, dividing major identity into four dimensions: major cognition, major emotion, major behavior and major environment cognition. Using Likert's five-point scale scoring method, all items are averaged. The higher the score is, the stronger the sense of identity in this major is. The internal consistency coefficient $\alpha$ of this questionnaire is 0.66 .

\subsubsection{Interview}

Semi-structured interview method is applied in this study, the purpose of which is to gain an in-depth understanding of students' career planning cognition, university's support for career planning, and the status of teacher's major curriculum implementation.

\subsection{Procedures}

In this study, the questionnaire was distributed to preschool education students in three grades. Based on the data analysis results, the researchers track and interview the extreme cases of each grade and ask relevant questions to supplement the analysis of the research results. SPSS 23.0 and Likert's five-point scale scoring method are used to record and analyze the data. Data is processed with descriptive statistics, $T$ test, and variance analysis .

\section{RESULTS}

\subsection{Overall characteristic analysis}

\subsubsection{Descriptive statistics for career planning}

\begin{tabular}{|c|c|c|}
\hline Items & Average & SD \\
\hline Career planning & 3.29 & 0.42 \\
\hline Self-cognition & 3.34 & 0.63 \\
\hline Environmental awareness & 3.31 & 0.61 \\
\hline Career planning knowledge mastery & 2.89 & 0.65 \\
\hline Career cognition & 3.53 & 0.57 \\
\hline
\end{tabular}

The mean and standard deviation of dimensions and total scores of career planning is shown in table 1 . The average score of career planning is 3.29 , which is slightly higher than the middle level. It means students' attitudes are generally positive. The mean score of career recognition is the highest, the mean score of career planning knowledge mastery is the lowest. The knowledge of students' career planning is relatively lacking. The mean values of self-awareness and environmental awareness are both higher than the mean of career planning, which means that students have a relatively strong understanding of self and environment. Except for the dimension of career planning knowledge mastery, the average score of other dimensions is higher than 3.00.

\subsubsection{Descriptive statistics for major identity}

\begin{tabular}{ccc} 
Table 2 & \multicolumn{3}{c}{ Descriptive statistics of major identity } \\
\hline Items & Average & SD \\
Major identity & 3.60 & 0.44 \\
Major cognition & 3.96 & 0.53 \\
Major emotion & 3.68 & 0.78 \\
Major behavior & 3.67 & 0.52 \\
Major environment cognition & 3.05 & 0.62 \\
\hline
\end{tabular}

The mean and standard deviation of dimensions and total scores of major identity is shown in table 2 . The mean score of major identity is 3.60, which is higher than middle level. To be specific, the mean score of major cognition is the highest, which can be explained by that students can be accessible to major classes directly and are provided with adequate cognitive opportunities. The mean value of major environment cognition is the lowest which demonstrates that the level of students' cognition towards major environment is comparatively low. The average score of major behavior and emotion are both higher than that of major identity. It shows that students conduct active major behaviors and have a positive feeling towards major. Additionally, all mean values of dimensions are higher than 3.00. 


\subsubsection{Career planning of students from different grades}

\begin{tabular}{|c|c|c|c|c|}
\hline & Grades & Mean & $\mathrm{SD} \quad F$ & $p$ \\
\hline \multirow{3}{*}{ Career planning } & Sophomore & 3.27 & 0.422 .99 & 0.06 \\
\hline & Junior & 3.19 & 0.41 & \\
\hline & Senior & 3.43 & 0.41 & \\
\hline \multirow{3}{*}{ Major cognition } & Sophomore & 3.29 & 0.650 .66 & 0.52 \\
\hline & Junior & 3.31 & 0.56 & \\
\hline & Senior & 3.45 & 0.70 & \\
\hline \multirow{3}{*}{ Environmental awareness } & Sophomore & 3.23 & 0.661 .07 & 0.35 \\
\hline & Junior & 3.27 & 0.50 & \\
\hline & Senior & 3.44 & 0.68 & \\
\hline \multirow{3}{*}{ Career planning knowledge mastery } & Sophomore & 3.04 & 0.611 .19 & 0.31 \\
\hline & Junior & 2.83 & 0.68 & \\
\hline & Senior & 2.83 & 0.65 & \\
\hline \multirow{3}{*}{ Career cognition } & Sophomore & 3.47 & 0.468 .44 & 0.00 \\
\hline & Junior & 3.34 & 0.55 & \\
\hline & Senior & 3.85 & 0.59 & \\
\hline
\end{tabular}

As is shown in table 3 , on the whole, the grade has no significant influence on students' career planning, self-awareness, environmental awareness and career planning knowledge mastery $(p>0.05)$. However, the career cognition of different grades students is significantly different $\left(F_{(2,102)}=8.4, p<0.01\right)$. Further results of the career cognition post-hoc test shows that the scores of senior students were significantly higher than those of sophomores $(\triangle \mathrm{M}=0.39, p<0.01)$, and junior students $(\triangle \mathrm{M}=0.52, p$ $<0.01)$. In addition, there was no significant difference between the sophomore students' career recognition score and junior students $(\triangle \mathrm{M}=0.13, p>0.05)$.

\subsubsection{Major identity of students from different grades}

\begin{tabular}{cccccc}
\multicolumn{6}{c}{ Table 4 Comparison of major identity in three grades } \\
\hline \multirow{4}{*}{ Major identity } & Grades & Mean & SD & $F$ & $p$ \\
\hline \multirow{5}{*}{ Major cognition } & Sophomore & 3.62 & 0.37 & 1.14 & 0.32 \\
& Junior & 3.52 & 0.45 & & \\
& Senior & 3.68 & 0.50 & & \\
& Sophomore & 3.77 & 0.49 & 10.03 & 0.00 \\
& Junior & 3.88 & 0.51 & & \\
& Senior & 4.28 & 0.46 & & \\
& Sophomore & 3.73 & 0.61 & 0.65 & 0.53 \\
Major emotion & Junior & 3.58 & 0.85 & & \\
& Senior & 3.77 & 0.87 & & \\
& Sophomore & 3.77 & 0.51 & 1.10 & 0.34 \\
Major behavior & Junior & 3.59 & 0.47 & & \\
& Senior & 3.67 & 0.57 & & \\
& Sophomore & 3.16 & 0.56 & 1.02 & 0.37 \\
Major environment cognition & Junior & 3.02 & 0.66 & & \\
& Senior & 2.95 & 0.62 & &
\end{tabular}

As is shown in table 4, generally, grade doesn't have a significant impact on major identity, major emotion, major behavior and major environment cognition of students $(p>0.05)$. Nevertheless, major cognition is significantly influenced by grade $\left(F_{(2,102)}=10.03, p<0.01\right)$. Further results of major cognition post-hoc test illustrate that the score of senior students is significantly higher than that of sophomore students $(\triangle M=0.51, p<0.01)$ and junior students $(\triangle M=0.41$, $p<0.01$ ). Additionally, there is no significant difference between the major cognition scores of sophomore and junior students $(\triangle \mathrm{M}=-0.10, p>0.05)$

\subsection{The relationship between different dimensions of career planning}

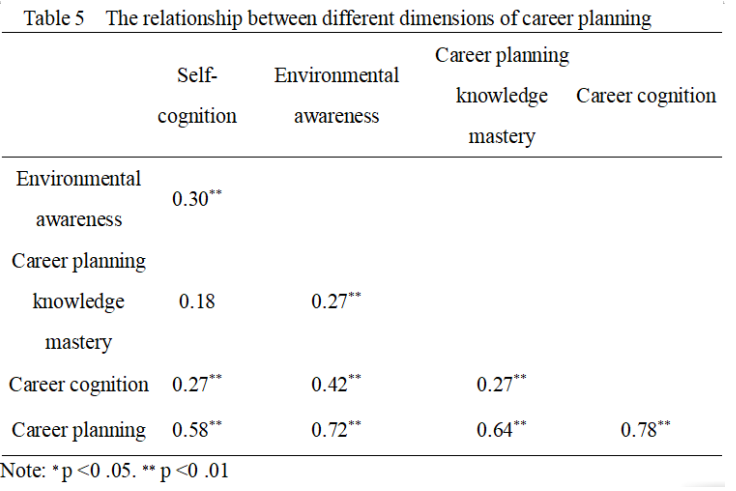

Related analysis results demonstrate the following conclusions:

1. Career planning is significantly positive related to its four dimensions, including self-cognition $(r=0.58, \quad p<0.01)$, environmental awareness $(r=0.72, p<0.01)$, career planning knowledge mastery $(r=0.64, p<0.01)$ and career cognition $(r=0.78, p<0.01)$

2. Each dimension is significantly related to each other except the relationship between self-cognition and career planning knowledge mastery.

(1) Environmental awareness is significantly positive related to self-cognition $(r=0.30, p<0.01)$. In the process of career planning, the student recognizing himself/herself clearly is more likely to have the ability to understand the environment well. (2) Career planning knowledge mastery is significantly positively related with self-cognition $(r=0.27, p<0.01)$. Career planning knowledge emphasizes that students should strengthen the understanding of their own in the process of career planning. Therefore, the acquaintance with such kind of knowledge improves students' self-cognition. (3) Career cognition is positively related with self-cognition $(r=0.27$, $p<0.01)$. Clear recognition about themselves helps students to set up career goals and learn more about the career deeply. (4) Career cognition is positively related with environmental awareness $(r=0.42, p<0.01)$. Career and environment cannot be detached. Hence, the clear understanding of career promotes students' awareness of environment, and learning environment more helps students to have a more rational and overall understanding of the career.(5) Career cognition is positively related with career planning knowledge mastery 
$(\mathrm{r}=0.27, \mathrm{p}<0.01)$. Students' mastery of career planning knowledge can be boosted by their more comprehensive knowledge about the types and characteristics of careers.

\subsection{The relationship between different dimensions of major identity}

\begin{tabular}{ccccc}
\multicolumn{4}{c}{ Table 6} & The relationship between different dimensions of major identity \\
\hline & $\begin{array}{c}\text { Major } \\
\text { cognition }\end{array}$ & $\begin{array}{c}\text { Major } \\
\text { emotion }\end{array}$ & $\begin{array}{l}\text { Major } \\
\text { behavior }\end{array}$ & $\begin{array}{c}\text { Major environment } \\
\text { cognition }\end{array}$ \\
\hline $\begin{array}{c}\text { Major emotion } \\
\text { Major behavior }\end{array}$ & $0.32^{* *}$ & $0.41^{* *}$ & $0.52^{* *}$ & \\
$\quad \begin{array}{l}\text { Major } \\
\text { environment } \\
\text { cognition }\end{array}$ & 0.10 & $0.38^{* *}$ & $0.26^{* *}$ & \\
$\begin{array}{c}\text { Major identity } \\
\text { Note: * } \mathrm{p}<0.05 .{ }^{* *} \mathrm{p}<0.01\end{array}$ & $0.59^{* *}$ & $0.85^{* *}$ & $0.76^{* *}$ & $0.61^{* *}$ \\
\hline
\end{tabular}

Related analysis results demonstrate the following conclusions:

1. Major identity is significantly positively related to its four dimensions, including major cognition $(r=0.59, p<0.01)$, major emotion $(r=0.85, p<0.01)$, major behavior $(r=0.76$, $p<0.01)$, major environment cognition $(r=0.61, p<0.01)$.

2 . Every dimension is significantly positively related with each other expect the relationship between major environment cognition and major cognition.

(1) Major emotion is positive related with major cognition significantly $(r=0.32, p<0.01)$. Active emotion towards major motivates students to learn more about the major. Also, deep understanding of major is beneficial for students to nurture the positive attitudes towards their own major. (2) Major behavior is positive related with major cognition significantly $(r=0.41, p<0.01)$. More active major behavior provides students with more chances of contacting the major which helps deepen major cognition. (3) Major behavior is positively related with major emotion significantly $(r=0.52$, $p<0.01)$. Students' positive major emotions can be cultivated by more frequent and active major behaviors. (4) Major environment cognition is positively related to major emotion significantly $(r=0.38, p<0.01)$. The positive evaluation of major environment is conducive to students' nurturing of positive major emotions. (5) Major environment cognition is significantly related to major behavior in a positive way $(r=0.26, p<0.01)$. The recognition of major environment encourages students to conduct more major behaviors. Also, high-qualified major behaviors play a fundamental role in students' active attitudes towards major environment.

\subsection{The relationship between major identity and career planning}

Table 7 The relationship between major identity and career planning

\begin{tabular}{|c|c|c|c|c|c|}
\hline & $\begin{array}{l}\text { Major } \\
\text { cognition }\end{array}$ & $\begin{array}{l}\text { Major } \\
\text { emotion }\end{array}$ & $\begin{array}{c}\text { Major } \\
\text { behavior }\end{array}$ & $\begin{array}{c}\text { Major } \\
\text { environment } \\
\text { cognition }\end{array}$ & $\begin{array}{l}\text { Major } \\
\text { identity }\end{array}$ \\
\hline Self-cognition & $0.26^{* *}$ & $0.42^{* *}$ & 0.13 & $0.21^{*}$ & $0.38^{* *}$ \\
\hline $\begin{array}{c}\text { Environmental } \\
\text { awareness }\end{array}$ & $0.35^{*+*}$ & $0.47^{* * *}$ & $0.49^{+*+\infty}$ & $0.20^{\prime \prime}$ & $0.54^{* * *}$ \\
\hline $\begin{array}{l}\text { Career planning } \\
\text { knowledge mastery }\end{array}$ & 0.07 & $0.24^{*}$ & $0.20^{*}$ & $0.37^{* *}$ & $0.32^{* *}$ \\
\hline Career cognition & $0.33^{* *}$ & 0.16 & $0.23^{*}$ & 0.13 & $0.28^{* *}$ \\
\hline Career planning & $0.37^{* *}$ & $0.45^{* *}$ & $0.39^{* *}$ & $0.32^{* *}$ & $0.54^{* *}$ \\
\hline
\end{tabular}

Career planning and major identity of preschool education students is significantly positively related $(r=0.54, p<0.01)$ Firstly, career planning is positively related with all dimensions of major identity significantly, including major cognition $(r=0.37)$, major emotion $(r=0.45)$, major behavior $(r=0.39)$ and major environment cognition $(r=0.32)$ Secondly, major identity is significantly positively related with all dimensions of career planning, including self-cognition $(r=0.38)$, environmental cognition $(r=0.54)$, career planning knowledge mastery $(r=0.32)$, and career cognition $(r=0.33)$.

All of the dimensions of career planning and major identity are related significantly, except the relationship between self-cognition and major behavior, career planning knowledge mastery and major cognition, career cognition and major behavior, career cognition and major environment cognition.

\section{DISCUSSION}

\subsection{Current situation of career planning}

As is found in this study, career planning is a little higher than middle level, which means students' attitudes towards career planning is a little positive. To be specific, firstly, the level of career cognition is the highest. With the help of interview, the study finds that the university provides students with stable internship platform in the long term starting from sophomore students. Students gradually obtain increasing opportunities for educational internship and practice, thus strengthening the understanding of careers. Previous researcher has proved that adequate social practice activities can help deepen students' understanding towards careers effectively. ${ }^{[9]}$ Secondly, self-cognition and environmental awareness is in the average level. This is consistent with Xiaoyu Zhang's research conclusion. Students lack a comprehensive and objective understanding of themselves and the environment, and they tend to assess themselves too high or extremely low. They may miscalculate the external environment, resulting in unrealistic career planning. ${ }^{[9]}$ However the research conducted by Dan Wu demonstrates that self-cognition of preschool education is comparatively high. This can be explained by that most of students' self-cognition are gained by others' analysis and self-assessment, which is lack a 
objectiveness. Therefore, it can be a quite different situation. [10] Thirdly, the level of career planning knowledge mastery is the lowest which can be found in Dan $\mathrm{Wu}^{[10]}$ and Wanying Dong's research. Because the quality of career planning activities is relatively low, and they lack systematic and comprehensive knowledge curriculum system. As is shown in further research, only $27.36 \%$ of undergraduates know the career planning curriculum and relating practical activities well organized by the university, and $29.75 \%$ of students consider that the career planning education of university is really useful.

The study illustrates that the career planning undergraduates between different grades is not significantly different. However, grade influences the career cognition significantly. To be specific, the career cognition of senior students is higher than that of sophomore and junior students significantly which is consistent with the results of Xiaoyu Zhang's research. ${ }^{[9]}$ After further interview, the study finds that the senior students can not only gain much more practical opportunities than lower grades, but also hold an more proactive attitude towards requirements of career entrance and career future prospects learning when they get into the internship period.

However, Min Chen's study shows that there is significant difference between career planning of postgraduate in different grades. ${ }^{[20]}$ It is likely because that the specialty of normal student's identity helps preschool education undergraduates to have a quite clear career goal when they are freshman.

\subsection{Current situation of major identity}

The results of this study demonstrate that major identity of students is relatively high which means most of students have a positive attitude towards this major. This result is consistent with that of $\mathrm{Zhi} \mathrm{Li}$ on undergraduates. ${ }^{[21]}$ Specifically, firstly, the level of major cognition is the highest. It is learned through interview that this university provides freshmen with chances of changing majors at the end of the first year. Students can enrich their knowledge about the major with the help of university's enlarged information sources and relating introductory lectures about preschool education. Secondly, the level of major environment recognition is the lowest. The problems of which mainly include the career counterparts which have a narrow occupation range, bleak development prospects, and salary and treatment that cannot reach the psychologically expected level. The most serious problem among them is the relatively low salary. $49.06 \%$ of students assume that the salary level is not as high as expected, which confirms the results of Yan Chen that there is a significant gap between reality and students' expectation towards future career in terms of salary and development space. ${ }^{[13]}$ Additionally, the social low recognition towards preschool education has been discovered through interview. Quite a large amount of individuals in the society is skeptical about the professional competence of preschool education undergraduates. Therefore, the major environment cognition of students is not high.
There is no significant difference between major cognition of students in different grades. However, grade can have an impact on major cognition of students significantly, which is demonstrated as major cognition of senior students is significantly higher than that of sophomore and junior students. It is discovered in the interview that senior students have completed all classes compared with other grades, which helps them to gain a thorough and systematic understanding of the curriculum setting system. Meanwhile, senior students are confronted with occupation selection, thus tend to learn more about norms and requirements of relating careers and strengthen professional knowledge and skills proactively.

\subsection{The relationship between major identity and career planning}

It is found in the study that major identity is positively related to career planning significantly, which means that the more positive the major identity is, the higher the level of career planning is. This is consistent with the results of Yi Wang. ${ }^{[17]}$ It is likely because that the students with more positive major identity may have a stronger willing to conduct occupations relating to that major, thus gaining career information and planning career in a more active way. Meanwhile, students can be encouraged to deepen professional learning and enriching major understanding, thereby enhancing students' major recognition.

Firstly, major identity is positively related to all dimensions of career planning (self-cognition, environmental awareness, career planning knowledge mastery, career cognition) significantly. Firstly, major identity is significantly positively related with self-cognition. Previous research demonstrates that there is a significant relationship between major identity and self-concept, which means major identity can be improved as self-concepts strengthened. ${ }^{[22]}$ According to Super's theory of major choice and development, choosing and developing major is the process of developing and using self-concepts in essential. [23] Self cognition belongs to self-concept. Therefore, the higher the level of self-cognition, the more active the major cognition is. Secondly, there is a significant positive relationship between major cognition and environmental awareness. The evaluation exerts an influence on major identity. ${ }^{[24]}$ Therefore, major identity can be heightened when the students' satisfaction of career environment is higher. Thirdly, major identity is significantly positively related with career planning knowledge mastery. Only when students recognize major well can they develop the awareness of exploring and planning for future career proactively, and then fulfill their individuals' values in careers. [25] Also, students' major identity depends on whether they make up a plan for their career in a rational and reasonable way, according to a previous study. ${ }^{[26]}$

Secondly, career planning is significantly positively related to all dimensions of major identity (major cognition, major emotion, major behavior and major environment cognition). Firstly, career planning is significantly related to major cognition and major environment cognition. It can be 
possibly explained by that the students is able to have a thorough understanding of career planning when they have a deep understanding of major and a good recognition of major objective environment. Secondly, there is a significant positive relationship between career planning and major emotion. The loyalty towards major is an active major emotion. According to previous research, major loyalty has a beneficial influence on career planning significantly. [27] Thereby, when undergraduates hold a positive emotion about major, they are apt to expect they can do relating jobs, thus conducting career planning actively. Thirdly, career planning is significantly related with major behavior. Students can also explore the gap between future career requirements and current competence in the process of career planning. Based on a deep understanding of the gap, self-improvement willingness of students can be applied to encourage major behavior.

\section{RECOMMENDATION}

\subsection{Strengthen self-cognition environmental awareness}

and

Self-cognition plays an indispensable role in career planning. However, the self-cognition is only in the average level according to this study. Therefore, two strategies are put forward: Firstly, students should explore their potentials deeply actively, which helps students to analyze themselves in terms of personal traits. Thus, students could gain a preliminary judgment and cognition. ${ }^{[1]}$ Secondly, it would be beneficial for students to know the evaluation on their own characteristic and competence from other people. ${ }^{[25]}$

Career environment factors exert an immense influence on personal career planning. As an individual, we are obliged to develop competence of choosing and adapting to the career environment in order to live up to personal goals and dreams. ${ }^{[28]}$ However, this study discovers that the level of career environmental recognition is only an average level. On the one hand, students should participate in lectures about preschool education career, and related practical activities. On the other hand, it is suggested that students should take part in classes duty and work in student union. According to a previous study, there is a high relationship between whether to attend in serving students and environment cognition competence. ${ }^{[29]}$

\subsection{Enhance career planning knowledge and competence}

Firstly, students should improve their learning activeness about career planning knowledge. For one thing, it is advised for students to learn career planning curriculum and textbooks provided by university carefully. For another, internet should be applied by undergraduates to collect career planning knowledge and learn systematically. Secondly, university should attach importance to the cultivation of students' career planning knowledge. For one thing, the cooperation between university and community is advocated, which provides students with opportunities of attending in community activities. For another, considering the speciality of normal students, internship and fieldwork are essential for preschool education undergraduates. Characteristics of careers can be explored and experienced by students in this process. Thirdly, parents are advised to support students' career planning. Parents can carry out activities about lectures, and introduce vocational knowledge in the university.

\subsection{Enhance major recognition}

For one thing, students should enhance their own major recognition actively. Firstly, strengths and self-characteristics can be combined to conduct career planning. As is found in this study, excellent career planning can improve major identity significantly. Secondly, favorable social support system should be constructed. Encountering major problems, students can turn to their friends. In this way, students can enhance their own major identity. For another, it is university's responsibility to nurture students' major cognition. Firstly, reasonable nutrition system for gifted people should be constructed. With the increased internship opportunities for undergraduates, students could deepen their understanding of major and strengthen their major in confidence. [ 30$]$ Secondly, university can attach more importance to preschool education major, set up more reasonable major curriculum and improve professional teachers' quality to provide favorable major learning environment for students. Thirdly, it is suggested for university to carry out employment guidance and training for students, which helps to elevate students' employment competence. University can also offer particular students personal guidance according to their traits and career priority. ${ }^{[15]}$

\section{CONCLUSION}

Career planning of preschool education major undergraduates is significantly related to major cognition. Both the scores of career planning and major cognition of undergraduates majoring in preschool education are higher than average level. However, the current situation of the grasp of major planning knowledge and major environment recognition is worrying. Finally, specific recommendations are proposed based on existing problems.

\section{REFERENCES}

[1] Bihui Chen. Theory of Career Planning Review. Beijing: Commercial Press, 2003, p. 90.

[2] Shuangping Luo. The concept and types of career planning. China Youth Study. 2003 No. 8, p. 6-7. 
[3] Tianzhou Zhang. Career Development and Planning. Taipei: Wunan Press, 1993, p. 165.

[4] Tickle-Degnen L. Teaching evidence-based practice. American Journal of Occupational Therapy. Vol.54(2000) No.5, p. 559-560.

[5] Jing Yang. Research and analysis of the major identity of college normal students-illustrated by Baicheng normal university.Vocational and Technical Education. Vol. 29 (2008) No. 8, p. 47-49.

[6]Wanying Dong. Problems and solutions for career planning education of normal undergraduates. Economic Research Guide. (2011) No.16, p. 248-249.

[7] Yan Wang: Research on present situation and countermeasures of college students' career planning in China-Take Taiyuan for example( D, Shanxi University of Finance \& Economics, China 2011). p. 33.

[8] Hui Zhan: Research on the Career Planning Education Within Normal Students in Jiangxi Universities (D, Jiangxi Normal University, China 2012). p.14.

[9] Xiaoyu Zhang: Research on the career planning of normal students: current situation, problems and countermeasures (D, Guangxi Normal university, China 2013). p. 25.

[10] Dan Wu: Research on the Current Situation and Strategies of the Career Planning for Students in Preschool Education-Take Changsha Normal College as An Example (D, Hunan Normal University, China 2012). p.36.

[11] Xiange Shi: The Issues and Strategies on Career Planning for graduates in Teachers' College (D, Guangxi Normal University, China 2008). p.23.

[12] Li Zhang. Research on major identity of preschool education vocational college students. Data of Culture and Education. Vol. 19 (2009), p. 232-234.

[13] Yan Chen, Ying Liang, Lijun Qiang. The Comparative Research of the Professional Identity of Undergraduate Students Major in Preschool Education. Studies in Preschool Education. (2008) No.03, p. 21-24.

[14] Xiaoli Liu: Relationship among Professional Identity, Professional Commitment and Learning Burnout of College Students Majored in Preschool Education (D, Shandong Normal University, China 2013). p.13

[15] Yu Long: The Research on Major Identity of Preschool Education Students in Normal Colleges (D, Hubei Normal University, China, 2016). p. 38

[16] Yuanzhen My, Li Zhang. Research on major identity of preschool education undergraduates. Modern Education Science. (2008) No. 08, p. 139-141+165.

[17] Yi Wang: A Study on the Relationship among Professional Identity, Career Planning and Subjective Well-being for Post Graduate ( D, Sichuan Normal University, China, 2015). p. 23.

[18] Rong An, Daosheng Hu. Current Situation and Influencing Factors of Career Identity of Higher Vocational Students_-Based on Investigation in Tianjin.
Vol.36 (2015) No.19, p. 63-67.

[19] Kaibing Wu: A Present Study on Preschool Education Major's Career Planning - Taking B University as an example (D, Chongqing Normal University, 2015). p. 7

[20] Min Chen: An Empirical Study on the graduate student career planning - take the E university as an example (D, East China Normal University, China, 2010). p. 37.

[21] Zhi Li, Qiqi Wang, Bingchun QI. Current Situation and Counterpart of Major Identity of undergraduate. Higher Education Exploration. (2011) No. 02, p. 131-136. [22] Zeshaung Jin: Relationship between Major Identity, Self-concept and achievement motivation of undergraduates (D, Hunan Normal University, 2011), p. 29.

[23] Yong Zhang. The Vocational Identity Research Approaches Based on Self Identity. Studies in Foreign Education. Vol. 37 (2010) No.04, p.43-47.

[24] Yuan Lin: Research on the current situation of professional identity of preschool education major in Chongqing (D, Chongqing Normal University, 2016). p. 48.

[25] Yan Li, Shengji Jin. Correlation between Profestional Identification and Personal Career Planning among Nursing Undergraduates. Vol. 28 (2011) No. 19, p. $5-7+57$.

[26] Juan Wang, Nianqiong Zhu. Undergraduate Career Planning and Its Significance to the Nursing Education. Journal of Nursing Science. (2006) No. 10, p.75-78.

[27] Jing Jiang: Research on Female Graduate Career Planning - Based on Education Discipline of H University ( D, East China Normal University, 2010). p. 68.

[ 28 ] Yongbao Liu: Study on the Issues and Countermeasures of College Students' Career Planning (D, Central China Normal University, 2007). p. 19.

[29] Kaiguo Qiu: Construction and Current Situation of Career Planning Skills of Undergraduates (D, Nangjing Normal University, 2008), p. 35.

[30] Hui Kong, Minrong Wu. Yanyun Wei. Research on Current Situation and Factors of Major Identity of Undergraduate. Education and Vocation. (2010) No. 29, p. 171-173. 